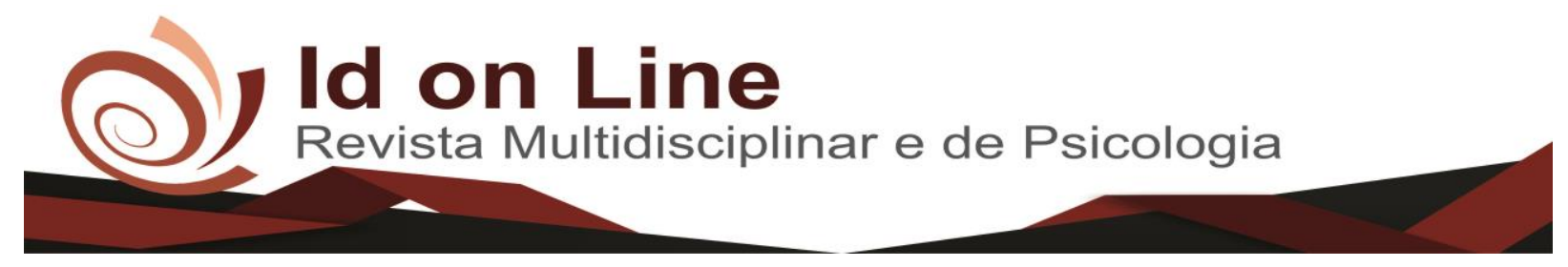

Artigo

\title{
A Percepção dos Profissionais de Contabilidade sobre o Estresse Laboral na Região do Cariri
}

\author{
Nayara Henrique Cavalache ${ }^{1}$, Larissa Vasconcelos Rodrigues ${ }^{2}$
}

\begin{abstract}
Resumo: O estresse está ligado ao cotidiano das empresas, faz parte do dia a dia do profissional passar por momentos de maior tensão e pressão psicológica. Embora exista uma dualidade de características, pode-se observar que existe o lado positivo e o negativo. $\mathrm{O}$ estresse está diretamente ligado ao ambiente em que se encontra o individuo, e hoje passou a ser considerado um dos maiores problemas da sociedade, e segundo Chiavenato (2010), é uma palavra de origem inglesa que significa pressão, tensão, e está relacionada com a carga de transtornos e aflições que certos eventos da organização, ou que estão em sua volta, provocam nas pessoas. Com o intuito de atingir o presente objetivo que o de investigar como os contadores reagem ao estresse na sua atuação profissional, esses profissionais atuam nas cidades da Região do Cariri interior do Ceará. O estresse pode ser entendido como reflexo da reação de um indivíduo discordar das exigências de uma atribuição ou da limitação pessoal para o cumprimento de tais exigências (SEEGERS; VAN ELDEREN, 1996). Segundo Paschoal e Tamayo (2004), o estresse derivado de fatores laborais pode ser considerado como estresse ocupacional de natureza física ou psicossocial, sendo que este último está mais ligado a conflitos organizacionais. Foi realizada uma pesquisa de opinião com o objetivo de analisar a percepção dos contadores sobre o estresse laboral. Esse tipo de pesquisa, de acordo com Lima (2018) consiste basicamente em medir atitudes, posicionamentos e opiniões acerca de determinado conteúdo pesquisado.
\end{abstract}

Palavras-Chave: Estresse laboral, contabilidade, tensão, pressão psicológica

\section{The Perception of Accountancy Professionals about Labor Stress in the Region of Cariri}

\begin{abstract}
Stress is linked to the daily life of companies, it is part of the daily life of the professional to go through moments of greater tension and psychological pressure. Although there is a duality of characteristics, it can be seen that there is both the positive and negative sides. According to Chiavenato (2010), stress is directly related to the environment in which the individual is, and today it is considered to be one of the major problems of society. It is a word of English origin that means pressure, tension and is related to the burden of disorders and afflictions that certain events of the organization, or that are around them, provoke in people. In order to reach the present objective, that of investigating how accountants react to stress in their professional performance, these professionals work in the cities of the Cariri region of Ceará. Stress can be understood as reflecting the reaction of an individual to disagree with the demands of an assignment or personal limitation to the fulfillment of such demands. According to Paschoal and Tamayo (2004), the stress derived from labor factors can be considered as occupational stress of a physical or psychosocial nature, the latter being more related to organizational conflicts. An opinion survey was conducted with the objective of analyzing the perception of accountants about work stress. This type of research, according to Lima (2018) basically consists of measuring attitudes, positions and opinions about certain content searched.
\end{abstract}

Keywords: Work stress, accounting, stress, psychological pressure

\footnotetext{
${ }^{1}$ Graduanda do curso de Administração do Centro Universitário Doutor Leão Sampaio. Juazeiro do Norte, Ceará - Brasil. Contato: nayarahenrique51@gmail.com;

${ }^{2}$ Especialista e docente do curso de Administração e Psicologia do Centro Universitário Doutor Leão Sampaio. Juazeiro do Norte, Ceará - Brasil. Contato: larissavasconcelospsi@gmail.com.
} 


\section{Introdução}

O estresse está ligado ao cotidiano das empresas, faz parte do dia a dia do profissional passar por momentos de maior tensão e pressão psicológica. Embora exista uma dualidade de características, pode-se observar que existe o lado positivo e o negativo. $\mathrm{O}$ ambiente organizacional ruim, a incoerência nas normas do trabalho e a sobrecarga de tarefas bem como eventuais conflitos, são exemplos comuns de fatores negativos, que por sua vez acarretam inúmeros prejuízos não só para a empresa no geral, mas principalmente prejuízos, sobretudo para a saúde, do colaborador.

Atualmente, as empresas estão inseridas em um ambiente cada vez mais competitivo e moderno devido a crescente necessidade de inovação, aumento substancial de informação bem como o melhoramento das técnicas administrativas.

Com a pressão das normas de trabalho, a sobrecarga de atividades e a cobrança no ambiente organizacional, a qualidade de vida do profissional fica cada vez mais comprometida, diminuindo sua produtividade, a qualidade do serviço prestado e, inversamente proporcional, aumentando a carga de estresse no indivíduo.

O estresse está diretamente ligado ao ambiente em que se encontra o indivíduo, e hoje passou a ser considerado um dos maiores problemas da sociedade, e segundo Chiavenato (2010), é uma palavra de origem inglesa que significa pressão, tensão, e está relacionada com a carga de transtornos e aflições que certos eventos da organização, ou que estão em sua volta, provocam nas pessoas. O profissional de contabilidade é um dos que mais sofrem com esse fato, pois desde o período acadêmico tem de lidar com a pressão mercadológica e psicológica no seu meio profissional.

Diante disso, surge o questionamento ao qual o presente estudo pretende investigar: Como os contadores lidam com os fatores estressantes da sua atuação profissional? Diante dessa questão, fez-se necessário o levantamento de algumas hipóteses, tais como: é possível que os contadores se distanciem do convívio social ou até mesmo adoecer e a redução da carga de trabalho ou intervalos mais longos reduzem o nível de estresse.

Com o intuito de atingir o presente objetivo que o de investigar como os contadores reagem ao estresse na sua atuação profissional, esses profissionais atuam nas cidades da Região do Cariri interior do Ceará, foram definidos os seguintes objetivos secundários: demonstrar características do comportamento de profissionais estressados; elencar e elucidar as formas e variáveis do 
estresse laboral e avaliar a viabilidade de meios para redução do estresse nesse ambiente de trabalho.

Acredita-se que a importância desta pesquisa se deu pela gravidade do problema abordado. Embora se trate de um tema muito abordado em diversas obras acadêmicas, o presente estudo traz uma proposta diferenciada que visa o aprofundamento específico nas causas reais da ocorrência do problema.

Dessa forma, o presente projeto justifica sua relevância acadêmica devido a pouca abordagem do tema nas pesquisas de trabalhos na área de administração, no âmbito social, pelo fato de que a pesquisa trará informações de meios de como reduzir o problema abordado existente em diversas classes trabalhistas bem como no aspecto pessoal do autor, uma vez que concluída a pesquisa, as novas informações serão levantadas irão ampliar o leque de conhecimento do pesquisador e, posteriormente serão comprovadas mediante futuras pesquisas de campo realizadas por outros pesquisadores motivados em face deste projeto.

\section{Estresse ocupacional}

O estresse pode ser entendido como reflexo da reação de um indivíduo discordar das exigências de uma atribuição ou da limitação pessoal para o cumprimento de tais exigências (SEEGERS; VAN ELDEREN, 1996). Devido ao grande avanço tecnológico as pessoas se tornaram cada vez mais dependentes do trabalho, dedicando cada vez mais horas do seu dia para atividades laborais, o que em excesso, acaba desencadeando problemas de saúde como o estresse.

Conforme Braga e Pereira (2011), o termo stress tem origem no latim e seu emprego era utilizado com a conotação de adversidade, porem no século XVIII passou a ser utilizado para referir-se a algo que se relaciona a pressão ou esforço. Mais tarde, Assis (2010), definiu o estresse como sendo o desgaste físico e emocional do indivíduo.

Ayres (2003), afirma que existe um lado positivo do estresse. Segundo sua afirmação, se o indivíduo, mesmo estando estressado, mantiver o controle da situação ele ainda pode sentir-se motivado para executar suas atividades. O mesmo ainda explica que, se ocorrer o contrário o indivíduo sofrerá com sintomas de grande cansaço, fadiga, descontrole emocional, déficit de atenção entre outros sintomas que vão comprometer e atrapalhar no rendimento das atividades do profissional. 
Segundo Paschoal e Tamayo (2004), o estresse derivado de fatores laborais pode ser considerado como estresse ocupacional de natureza física ou psicossocial, sendo que este último está mais ligado a conflitos organizacionais.

Se levar em conta que o profissional de contabilidade está sujeito ao estresse ocupacional e que a contabilidade sobre influências do comportamento dos indivíduos, logo pode-se considerar que o estresse ocupacional poderá desencadear reflexos no preparo das demonstrações contábeis.

\section{O contador e suas responsabilidades}

A contabilidade tem um papel fundamental para as empresas em suas tomadas de decisão, pois através de suas demonstrações, as organizações podem mensurar o estado de suas riquezas e patrimônio.

O profissional de contabilidade precisa sempre estar atualizado quanto a suas habilidades em relação aos seus colegas de trabalho, por esse motivo, muitos desses profissionais abrem mão do lazer, descanso e outras atividades que lhe proporcione bem estar para garantir essa vantagem (IUDÍCIBUS, 1991).

O trabalho de um contador tem como finalidade, a análise de documentos, exigindo metas a cumprir e data prevista, levando o profissional ser extremamente atencioso e criterioso nas análises. De acordo com o site da Infojobs, cabe ao contador organizar e executar serviços de contabilidade em geral, escrituração dos livros de contabilidade obrigatórios, organização e levantamento dos respectivos balanços e diversas outras atribuições.

Em suma, de acordo com Marion (2000), a função primaria do profissional de contabilidade é fornecer informações contábeis aos gestores a fim de auxilia-los nas suas tomadas de decisões. Lisboa (1997), completa que o contador fornece essas informações a diversas pessoas de acordo com seu tipo de necessidade sem visar benefício próprio

De acordo com Thomé (2001), a rotina e a demanda desse profissional é enorme, pois suas responsabilidades estão divididas em uma série de diversos segmentos menores, em se tratando da prestação de serviços aos seus clientes. Ele cita que além de controlar todo o patrimônio da empresa, o mesmo ainda tem de informar toda a atual situação do empreendimento, através de informações coletadas com os clientes e fornecedores. 
Com isso o indivíduo chega a fadiga mental e física, tendo outras funções derivadas ao contador que o obriga a se dedicar mais tempo ao trabalho e serviços a concluir. Desse modo, o trabalho cega o contador dos fatores que levam o indivíduo a exaustão e consequentemente ao estresse, mantendo-o focado somente em ganhos financeiros e em ganhar uma promoção.

\section{O estresse no ambiente profissional}

De acordo com Ballone e Moura (2008), existem diversos fatores na sociedade que favorecem a incidência e ao aumento do estresse no cotidiano das pessoas. Selye (1995) apud Veloso e Pimenta (2004) complementa essa informação afirmando que fatores como a rigidez exacerbada imposta pela organização sobre o profissional o que leva a impossibilidade da realização de suas próprias atribuições. Outros estudos relacionados à temática em questão foram realizados a fim de correlacionar os fatores causadores do estresse e sua influência na vida profissional das pessoas.

Segundo o estudo feito por Vieira et. al. (2012), que buscou apontar o grau bem como os sintomas do estresse laboral em profissionais da contabilidade. Constatou-se na pesquisa de Vieira et. al. (2012) que 50\% dos participantes não apresentam indícios de estresse, 35\% na chamada fase de resistência, onde o indivíduo reluta em não ceder à pressão psicológica e por fim, 13\% encontram-se em esgotamento, ou seja, exauridos com a rotina altamente estressante.

Um estudo mais complexo proposto por Fraga (2004) investigou os níveis de estresse em profissionais da medicina. O objetivo foi de confirmar a presença da doença, em qual estágio se encontra, qual a prevalência dos sintomas entre físicos e psicológicos e verificar as possíveis relações dos fatores causadores de estresse com o exercício da função profissional. Os resultados dessa pesquisa apresentaram que $72 \%$ dos médicos sofrem apresentam um quadro de estresse, outros $78 \%$ se encontram em um quadro de resistência e por fim, $22 \%$ foram considerados em fase de exaustão. A pesquisa ainda mostra que em $43 \%$ dos médicos considerados estressados sofrem predominantemente de sintomas psicológicos, enquanto que 35\% sofrem com sintomas físicos e os outros $22 \%$ sofrem de ambos os sintomas, tanto físico quanto psicológico. E na conclusão da pesquisa, considera-se que os fatores de origem organizacional são possivelmente causadores do estresse. 


\section{Causas e consequências do estresse laboral em profissionais de contabilidade}

Devido ao alto grau de responsabilidade, exigências mercadológicas bem como a grande concorrência entre os profissionais contadores, é completamente compreensível os índices de grandes níveis de estresse em ambientes laborais nos escritórios de contabilidade. Ballone e Moura (2008) ratifica essas premissas quando destaca ainda que fatores relacionados à ocorrência do estresse laboral são a falta de apoio e ainda as expectativas exacerbadas deles próprio bem como das pessoas que as rodeiam.

De acordo com Lipp e Malagris (2001), os fatores denominados "estressores" ou fontes do estresse, podem ser originados por meios de fontes internas ou externas ao indivíduo. $\mathrm{O}$ autor cita como exemplo, fatores ligados a problemas financeiros, problemas ou perdas familiares, desentendimentos com amigos, colegas de trabalho, colegas de faculdade ou família, fatores externos. Já fatores ligados a crenças, costumes e tradições, princípios e valores são relacionados a fatores externos.

Segundo a Isma Brasil (2014), de todos os principais fatores geradores de estresse, o mais agravante é a falta de tempo para a realização de cada vez atividades, ou seja, a sobrecarga de trabalho é o principal adversário dos profissionais contadores ao tentarem levar uma vida com bem-estar, a pesquisa realizada mostra que $64 \%$ dos participantes apontam o excesso de trabalho como a principal causa de seus sintomas de estresse laboral.

Conforme Lipp e Malagris (2001) os fatores relacionados à todas as causas citadas acima ocasionam sintomas como cansaço mental, fadiga, desgastes físicos e até mesmo surgimento de doenças antes não contraídas. A Isma Brasil (2014) constatou que $70 \%$ dos profissionais brasileiros sofrem de alguma consequência decorrente do estresse laboral, e desses, $30 \%$ sofrem do mais alto nível de estresse conhecido como Síndrome de Bornout, que consiste no esgotamento mental intenso ocasionado pela pressão psicológica sofrida no ambiente de trabalho. Nesse sentido, Zille e Cremonezi (2013), relaciona o estresse laboral a um desequilíbrio expressivo entre as exigências de trabalho que lhes são impostas à sua capacidade de reação e atendimento das demandas solicitadas onde o não cumprimento destas pode levar a consequências muito gravosas, como por exemplo, o profissional chegar a um quadro depressivo em casos extremos. 


\section{Metodologia}

Nessa seção serão apresentados os métodos científicos utilizados para coleta de dados da pesquisa.

A princípio, o projeto caracteriza-se como um estudo descritivo exploratório, que descreve características de uma determinada população ou fenômeno de acordo com Pereira (2012) e ao mesmo tempo mostra aspectos objetivos e subjetivos, enquanto que os objetivos específicos da pesquisa terão uma abordagem qualitativa que, conforme Andrade, Guimarães e Assis (2010, p. 6), caracteriza-se "pela imersão do pesquisador no contexto a ser pesquisado, onde ele é um interpretador desse pedaço de realidade".

O presente projeto teve como os sujeitos de pesquisa os profissionais contadores que atuam no ramo de contabilidade em algumas cidades da Região do Cariri como também em cidades próximas. Conforme Marion (2000) este é o profissional encarregado de trabalhar com a área financeira, econômica e patrimonial de uma ou de várias pessoas jurídicas.

Foi realizada uma pesquisa de opinião com o objetivo de analisar a percepção dos contadores sobre o estresse laboral. Esse tipo de pesquisa, de acordo com Lima (2018) consiste basicamente em medir atitudes, posicionamentos e opiniões acerca de determinado conteúdo pesquisado. As pesquisas de opinião podem seguir várias vertentes, mas quando se é posicionada para o viés político, essa então é considerada pesquisa política ou pesquisa eleitoral.

A análise dos dados realizou-se de maneira detalhada, observando qualitativamente a concordância em todas as respostas dos participantes da pesquisa. Caso haja alguma disparidade nas respostas ou divergência de opiniões, o pesquisador tratará de readequar as perguntas feitas, afim de equalizar o conteúdo investigado com as respostas obtidas, conforme descreve o conceito proposto por Creswell (2007).

Como se trata de uma pesquisa de opinião os riscos considerados potenciais na presente pesquisa consistem basicamente no desinteresse do alvo da pesquisa em contribuir com sua participação e colaboração na resposta do questionário.

Os principais benefícios são demonstrar os níveis de estresse laboral provenientes da profissão do contador, bem como através da pesquisa de opinião analisar a percepção destes profissionais a respeito do estresse laboral. 


\section{Análise e Discussão dos Resultados}

O autor da pesquisa buscou através deste trabalho, elucidar os desafios enfrentados por profissionais de contabilidade ao lidarem com o estresse laboral, a fim de auxiliar na busca por uma melhor qualidade de vida bem como uma rotina de trabalho menos estressante e objetiva, para isso foi utilizado o modelo de coleta de dados proposta pela metodologia desta pesquisa. Os resultados obtidos através dos participantes foram tabulados e analisados na presente seção.

Gráfico 1: Gênero

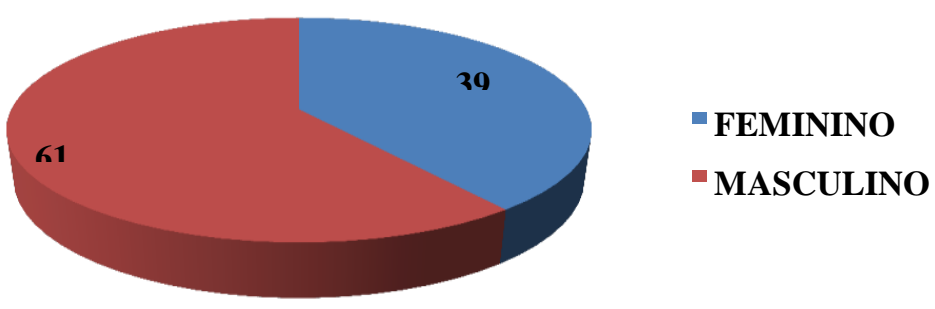

Fonte: Dados da pesquisa (2018)

Conforme os gráficos 1 abaixo, em suas características gerais, os participantes da pesquisa em sua maioria são do sexo masculino, correspondendo a $61 \%$ dos participantes.

Gráfico 2: Estado civil

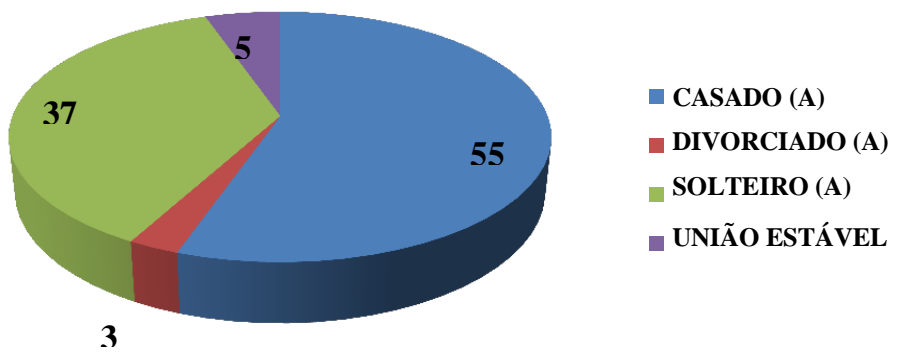

Fonte: Dados da pesquisa (2018)

De acordo com o gráfico 2, 55\% dos participantes são casados e 37\% são solteiros. Apenas um pequeno percentual de $5 \%$ e $3 \%$ correspondem à aqueles que se 
encontram em uma união estável ou divorciados, respectivamente.

Gráfico 3: Nível de escolaridade

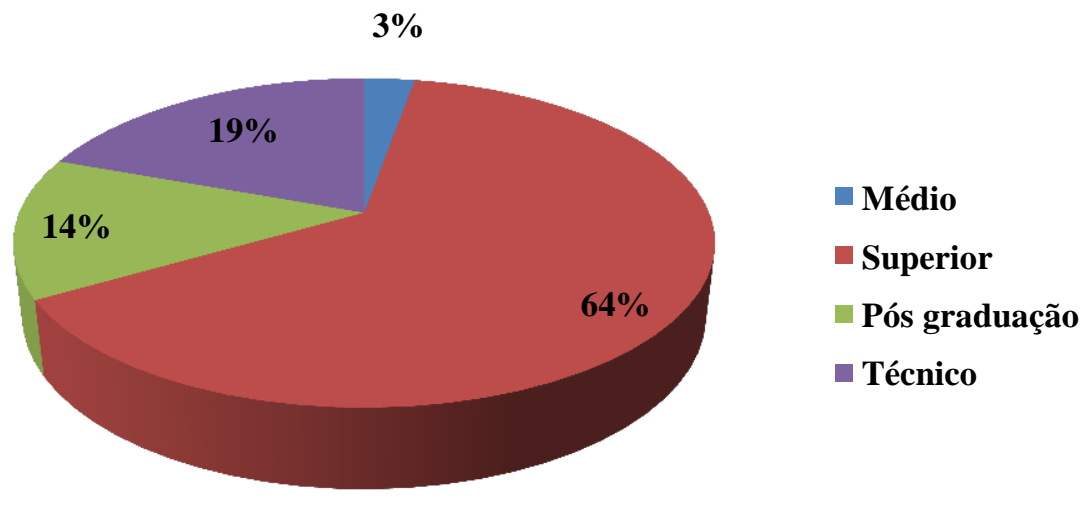

Fonte: Dados da pesquisa (2018)

Em relação ao nível de escolaridade dos participantes, majoritariamente possui no mínimo o ensino superior, são $64 \%$ dos participantes formados nos cursos de contabilidade e administração de empresas. Outros 14\% correspondem aos participantes que possuem pósgraduação em seu nível de escolaridade. Existem também aqueles que atuam escritórios de contabilidade mesmo sem a graduação na área específica, é o caso dos profissionais técnicos, que nessa pesquisa correspondem a $19 \%$ dos participantes.

Gráfico 4: Há quanto tempo trabalha como contador

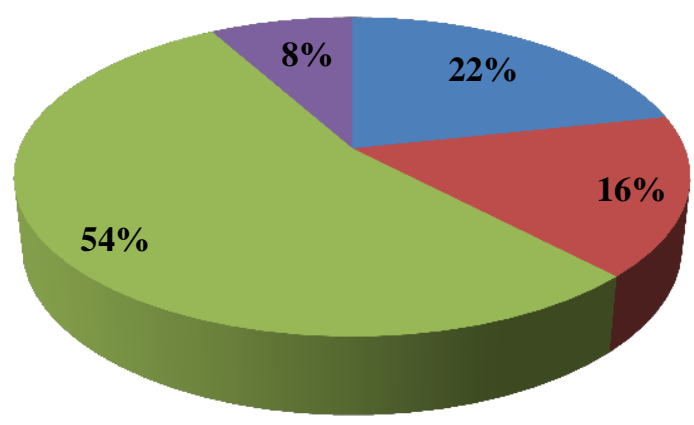

- Entre 2 a 3 anos

- Entre 4 a 6 anos

- Mais de 7 anos

- Menos de 1 ano

Fonte: Dados da pesquisa (2018) 
De acordo com o gráfico 4 os profissionais participantes da pesquisa já atuam na área há muitos anos. São 54\% dos profissionais atuantes há mais de 7 anos, 16\% trabalham entre 4 e 6 anos e outros $22 \%$ atuam entre 2 e 3 anos. Isso mostra que os profissionais pesquisados estão consideravelmente propensos a sofrerem de sintomas de estresse laboral devido ao longo período de tempo exercendo as repetidas funções, bem como atenderem a todas as exigências do mercado a adaptações às mudanças no perfil dos clientes e também do mercado.

Gráfico 5: Você sabe o que é estresse laboral?

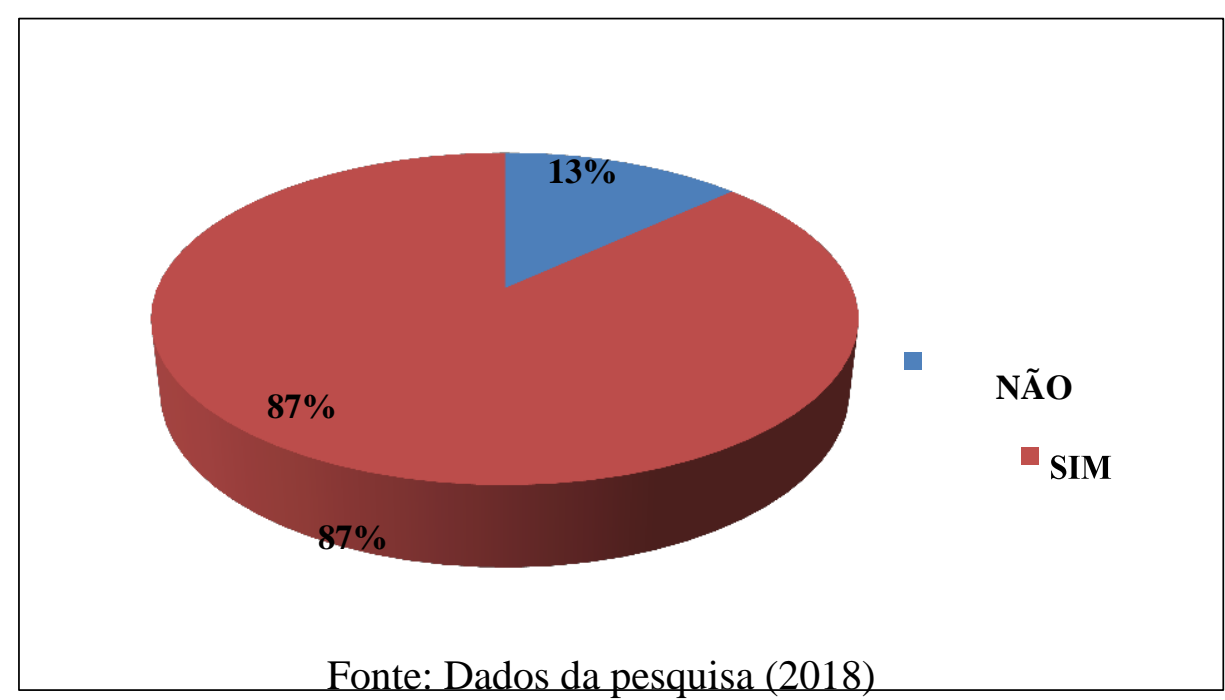

Conforme demonstrado no gráfico 5, a grande maioria dos participantes da pesquisa demonstram ter conhecimento, ao menos prévio, do que se trata o estrese laboral. Isso pode levar a considerar que em algum momento da carreira, esses profissionais já vivenciaram ou visualizaram uma situação desse tipo. De acordo com o referencial deste trabalho, Lipp e Malagris (2001) bem como Isma Brasil (2014) destacam diversos exemplos de sintomas resultantes do acumulo de estresse laboral, dentre os quais se destacam o cansaço mental, a fadiga e dores físicas. 
Gráfico 6: Principais sintomas do estresse
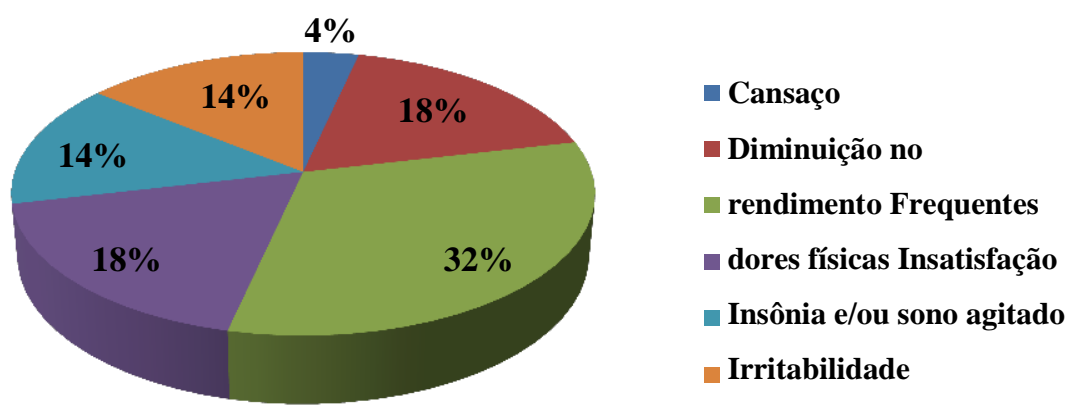

Fonte: Dados da pesquisa (2018)

Como visto no gráfico 6, foram listados vários sintomas decorrentes do estresse vivenciado no ambiente organizacional. Dentre os principais citados no gráfico, o sintoma que mais afeta aos profissionais são dores físicas com frequência, como dores de cabeça, dores musculares e outras conforme fora mencionado por Lipp e Malagris (2001), onde fadiga, cansaço mental e desgastes físicos são resultados das fontes do estresse no profissional, sobretudo o contador.

Gráfico 7: Acredita que o ambiente influencia no desencadear do estresse?

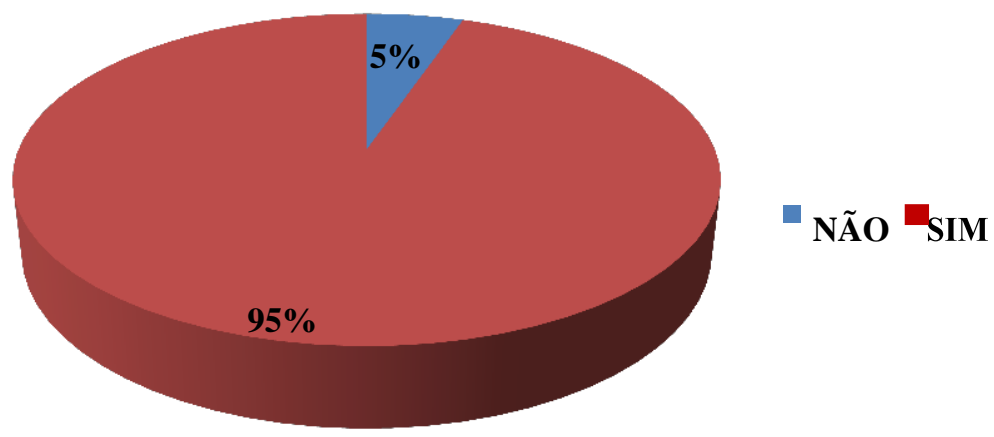

Fonte: Dados da pesquisa (2018) 
No gráfico 7 , pode se observar que quase totalidade dos participantes da pesquisa concordam que o ambiente pode sim ocasionar ou até mesmo agravar um cenário estressante entre os profissionais. Esses dados corroboram com a afirmação de Tamayo (2004), onde o autor diz que o estresse derivado de fatores laborais pode ser considerado como estresse ocupacional de natureza física ou psicossocial.

Gráfico 8: Você conhece alguém que foi afastado devido ao estresse laboral?

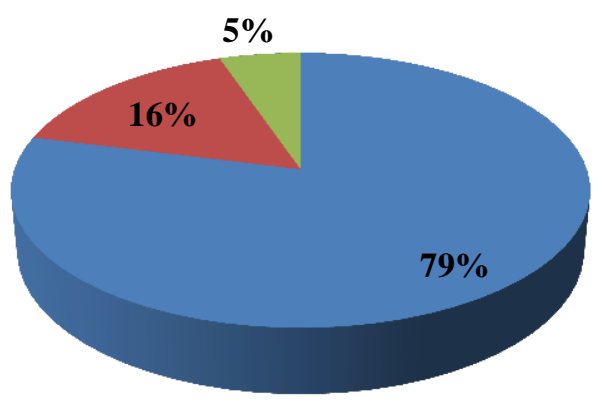

\author{
- Não conheço nenhuma \\ pessoa \\ - Sim, conheço 1 pessoa \\ Sim, conheço entre 2 a 3 \\ pessoas
}

Fonte: Dados da pesquisa (2018)

No gráfico 8 embora todos os indícios e sintomas prejudiciais a saúde física e mental apresentados pelo referencial teórico bem como os resultados obtidos até aqui com este trabalho, $79 \%$ dos participantes da pesquisa afirmaram que não conhecem ninguém que tenha sido afastado por motivos de debilitação por estresse laboral acumulado.

Esse dado entra em discordância uma vez que a pesquisa da Isma Brasil (2014) afirma que $64 \%$ dos profissionais pesquisados por ela sofrem com o excesso de trabalho, e esse fator é apontado pela mesma como uma das principais causas de estresse laboral, o que consequentemente poderia levar o profissional a um quadro clínico ainda pior. 
Gráfico 9: Quais as principais causas para o estresse laboral?

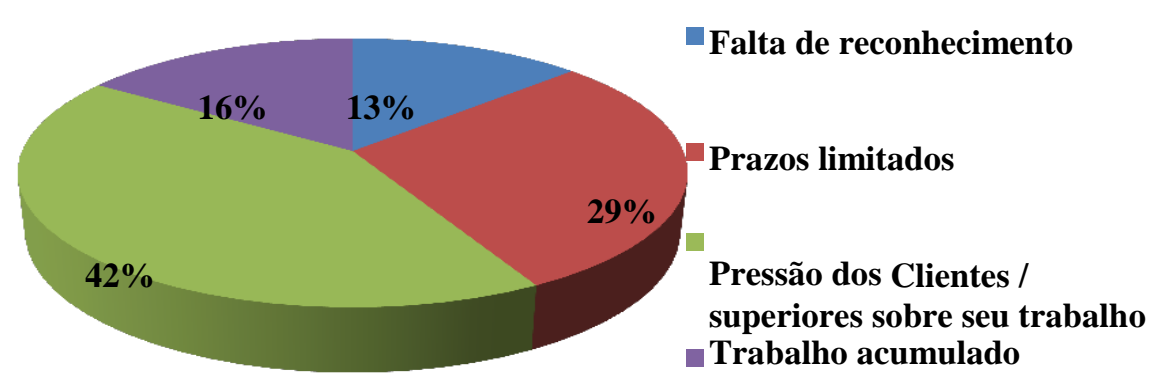

Fonte: Dados da pesquisa (2018)

Para os participantes da pesquisa, as principais causas para a incidência do estresse laboral é a pressão dos clientes e superiores em cobranças de seu trabalho, apontado por $42 \%$ dos pesquisados, seguido de perto com $29 \%$ dos participantes apontam os prazos curtos para entrega de suas demandas. Esses dados completam a afirmação de Zille e Cremonezi (2013) pois o autor relaciona o estresse laboral com um expressivo desequilíbrio entre as exigências impostas no trabalho e a capacidade de reação e suprimento das demandas atribuídas aos profissionais.

Gráfico 10: Nos períodos de maior demanda, você se sente estressado?

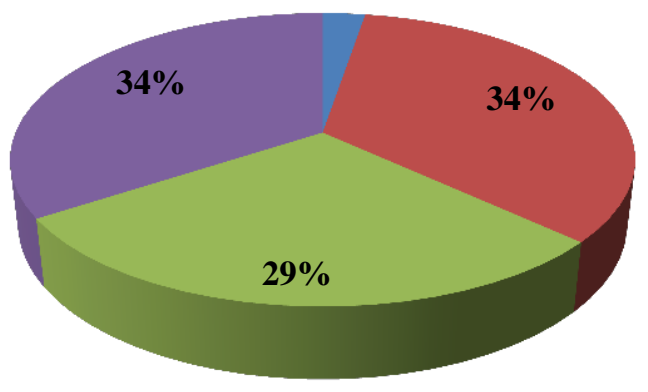

- Nunca

- Quase sempre

Raramente

- Sempre

Fonte: Dados da pesquisa (2018) 
No gráfico 11 constata-se que em períodos de alta demanda e cobranças no trabalho, os profissionais contadores sempre ou quase sempre sentem-se estressados devido seu trabalho, geralmente em períodos em que se precisa fazer a declaração de Imposto de Renda para a Receita Federal.

\section{Considerações Finais}

Seguindo a proposta inicial do trabalho a fim de atingir os objetivos, geral e específicos, determinados pelo autor, a pesquisa buscou elucidar a correlação entre as principais causas do estresse laboral em profissionais contadores e suas consequências em relação ao desempenho das atividades profissionais.

Ao verificar como esses profissionais lidam com esse fenômeno, constatou-se que em muitos casos os profissionais pesquisados sofrem dos mesmos, ou parecidos, sintomas descritos no referencial teórico do presente estudo. A grande maioria dos participantes da pesquisa trabalha e reside nas cidades situadas na Região do Cariri, sobretudo na cidade de Juazeiro do Norte-CE.

A pesquisa mostrou em seus resultados um perfil de profissional aparentemente maduro e com alto nível de escolaridade, onde a grande maioria é formada na área profissional seja na área acadêmica ou técnica e até mesmo em nível superior em outras áreas do conhecimento. São profissionais que já atuam há bastante tempo na área e por isso, a pesquisa revelou que a grande maioria dos participantes da pesquisa afirmaram que sabem do que se trata o assunto pesquisado, estresse laboral.

Os mesmos citaram em suas respostas as principais causas para a ocorrência desse problema no meio profissional, e o fato é que a maioria das respostas obtidas com a pesquisa corroboram com o que foi levantado no referencial teórico do estudo. O mesmo ocorreu com as respostas obtidas ao questionar sobre os sintomas aparente devido o estresse. Tanto sintomas físicos quanto psicológicos foram citados na pesquisa, e basicamente os mesmos sintomas foram relatados nas respostas pelos participantes da pesquisa.

Por fim, ao serem indagados sobre sua opinião sobre o fato do ambiente proporcionar um maior índice de estresse, quase que unanimidade concordam que sim e completam afirmando que dependendo do período, o nível de estresse pode ser tão alto quanto a demanda 
exigida pelos seus clientes. Contudo, a presente pesquisa conclui que seu principal objetivo fora atingido de modo que deixa também em aberto a possibilidade de um futuro aprofundamento no assunto e que este projeto sirva de base de estudos e pesquisas acadêmicas.

\section{Referências}

ANDRADE, C. R. de; GUIMARÃES, L. V. M.; ASSIS, L. B. Análise Crítica das Pesquisas em Estresse Ocupacional da Anpad: Afinal, Cadê o Sujeito? XXXIV EnANPAD. Rio de Janeiro, setembro, 2010.

AYRES, K. V.; CAVALCANTI, G. A.; BRASILEIRO, M. do C. E. Stress Organizacional: O Caso das Empresas de Base Tecnológica Incubadas da Região Nordeste. EnANPAD, 2001.

BRAGA, C. D.; PEREIRA, L. Z. Relação Entre a Função Gerencial e o Estresse Ocupacional: Uma análise a partir do Impacto das Novas Tecnologias de Gestão. III EnGPR (III Encontro de Gestão de Pessoas e Relações de Trabalho). Anais... João Pessoa, novembro 2011.

BALlONE, G. J.; MOURA, E. C. Estresse: o que é isso? Disponível em: <http://www.psiqweb.med.br>, revisto em 2008. Acesso em: 23 Out. 2018.

CHIAVENATO, I. Comportamento Organizacional. 2 ed. Rio de Janeiro: Elsevier, 2010.

CRESWELL, J. W. Projeto de Pesquisa: Método qualitativo, quantitativo e misto. Porto Alegre: Artmed, 2007.

FRAGA, G. S. Ambiente de Trabalho, Estresse e Saúde em Médicos da Rede Municipal de Saúde de Goiânia. 2004. Disponível em: <http://tede.biblioteca.ucg.br/tde_arquivos/10/TDE -2005-0519T104948Z- 50/Publico/Gutemberg\%20da\%20Silva\%20Fraga.pdf>. Acesso em: 04 Nov. 2018.

IUDÍCIBUS, S. Contabilidade: uma visão crítica e o caminho para o futuro. Belo Horizonte: CRC/MG, 1991.

LIPP, M. E. N.; MALAGRIS, L. E. N.. O stress emocional e seu tratamento. In: B. Rangé (Org). Psicoterapias cognitivo-comportamentais: um diálogo com a psiquiatria (p. 475-490). Porto Alegre: Artmed, 2001.

LISBOA, L. P. Ética geral e profissional em contabilidade. Fundação Instituto de Pesquisas Contábeis, Atuariais e Financeiras. 2. ed. São Paulo: Atlas, 1997.

LIMA, A. F. Pesquisa de opinião pública. Apostila de opinião pública. Curso de Gestão em Políticas Públicas FAPSS-SCS. Disponível em: <

https://www.ebah.com.br/content/ABAAAAqpMAA/apostila-pesquisa-opiniao- publica> Acesso em 31 Out 2018.

MARION, J. C.; MARION, M. M. C. O ensino da contabilidade no Brasil. São Paulo: Atlas, 2000.

PASCHOAL T.; TAMAYO, A. Validação da escala de estresse no trabalho. Revista Estudos de Psicologia, v. 9, n. 1, p. 45-52, 2004. 
PEREIRA, J. M. Manual de Metodologia da Pesquisa Científica. São Paulo: Atlas, 2012.

SEEGERS, G.; VAN ELDEREN, T. Examining a model of stress reactions of bank directors. European Journal of Psychological Assessment, v. 12, n. 3, p. 212-223, 1996.

THOMÉ, Irineu. Empresas de Serviços Contábeis: Estrutura e Funcionamento. São Paulo. Editora Atlas 2001.

VELOSO, H. M.; PIMENTA, S. M. Fontes de Pressão e as Novas Configurações do Trabalho: Uma discussão sobre os Modelos de Análise Estresse Ocupacional Frente à Realidade Bancária. EnANPAD, 2004.

VERGARA, S. C. Projetos e relatórios de pesquisa em administração. 3. ed. São Paulo: Atlas, 2000.

VIEIRA, S. S. da C. et. al. Análise do nível de estresse do profissional de Contabilidade. 2012. Disponível em: < htp:/dx.doi.org/10.507/ 2175- 8069.2012v9n18p103>. Acesso em: 04 Nov. 2018.

\section{Como citar este artigo (Formato ABNT):}

CAVALACHE, Nayara Henrique; RODRIGUES, Larissa Vasconcelos. A Percepção dos Profissionais de Contabilidade sobre o Estresse Laboral na Região do Cariri. Id on Line Rev.Mult. Psic., 2018, vol.12, n.42, Supl. 1, p. 465-480. ISSN: 1981-1179.

Recebido: 08/11/2018;

Aceito: 09/11/2018 